\title{
In vitro evaluation of antiviral and virucidal activity of a high molecular weight hyaluronic acid
}

\author{
Claudio Cermelli ${ }^{1}$, Alessandro Cuoghi ${ }^{1}$, Monica Scuri ${ }^{2}$, Clotilde Bettua $^{1}$, Rachele G Neglia', Andrea Ardizzoni ${ }^{1}$, \\ Elisabetta Blasi ${ }^{2}$, Tommaso lannitti ${ }^{3^{*}}$ and Beniamino Palmieri ${ }^{4}$
}

\begin{abstract}
Background: hyaluronic acid (HA), a non-sulphated glycosaminoglycan, is present in synovial fluid, vitreous humour serum and many connective tissues. Pharmaceutical preparations of HA are used in clinical practice for wound healing, joint pain, kerato-conjunctivitis, asthma, mouth care, oesophageal-reflux, and gastritis. Moreover, it is used as a filler to counteract ageing and facial lipoatrophy. Our study aims at investigating the in vitro antiviral activity of a high molecular weight HA.
\end{abstract}

Methods: the MTT test was used to rule out the potential toxic effects of HA on the different cell lines used in the antiviral assays. The antiviral activity of HA against Coxsackievirus B5, Herpes Simplex Virus-1, Mumps Virus, Adenovirus-5, Influenza Virus A/H1N1, Human Herpesvirus-6, Porcine Parvovirus, Porcine Reproductive and Respiratory Syndrome Virus was assessed by virus yield assays.

Results: the most effective inhibition was observed against Coxsackievirus B5, with 3 Log reduction of the virus yield at $4 \mathrm{mg} / \mathrm{ml}$, and a reduction of $3.5 \mathrm{Log}$ and $2 \mathrm{Log}$, at $2 \mathrm{mg} / \mathrm{ml}$ and $1 \mathrm{mg} / \mathrm{ml}$, respectively: the selectivity index was 16. Mumps virus was highly inhibited too showing a reduction of $1.7 \mathrm{Log}$ at $1 \mathrm{mg} / \mathrm{ml}$ and $1 \mathrm{Log}$ at $4 \mathrm{mg} / \mathrm{ml}$ and $2 \mathrm{mg} / \mathrm{ml}$ (selectivity index = 12). The selectivity index for Influenza Virus was 12 with the highest inhibition (1Log) observed at $4 \mathrm{mg} / \mathrm{ml}$. Herpes Simplex Virus-1 and Porcine Parvovirus were mildly inhibited, whereas no antiviral activity was observed with respect to Adenovirus-5, Human Herpesvirus-6, Porcine Reproductive and Respiratory Syndrome Virus. No HA virucidal activity was ever observed against any of the viruses tested. Kinetic experiments showed that both Coxsackievirus B5 and Herpes simplex virus-1 replication were consistently inhibited, not influenced by the time of HA addition, during the virus replication cycle.

Conclusions: the spectrum of the antiviral activity exhibited by HA against both RNA and DNA viruses, known to have different structures (with or without envelope) and replication strategies, suggests a non specific mechanism of action, probably involving cell membrane-virus interaction steps. The results of the kinetic experiments support this hypothesis.

\section{Introduction}

Hyaluronic acid (HA) is a non-sulphated glycosaminoglycan which consists of alternately repeating D-glucuronic acid and $\mathrm{N}$-acetylglucosamine units. A huge variety of HAs, with different molecular weights, has been described, probably retaining distinct physicochemical

\footnotetext{
* Correspondence: tommaso.iannitti@gmail.com

${ }^{3}$ Department of Biological and Biomedical Sciences, Glasgow Caledonian University, Glasgow, UK

Full list of author information is available at the end of the article
}

and biological properties. HA is naturally present throughout all mammalian systems, especially synovial fluid, vitreous humour serum and many connective tissues [1]. Moreover, HA is found intercellularly in connective tissues, such as skin, combined with proteins and chondroitin sulphate, where it fulfills important functions involved in tissue structure maintenance, moisture and lubrication [2].

Initially introduced in clinical practice as wound healing promoter, HA is currently used in many medical 
and cosmetic fields. Some examples of HA applications include eye drops for kerato-conjunctivitis, intra-articular injections for osteoarthritic joint pain, irrigations for bladder and vaginal chronic inflammatory disorders, tracheobronchial aerosolization for asthma, oral solutions for mouth care or for oesophageal-reflux and gastritis. Besides, HA is commonly used for cosmetic interventions, as a filler to counteract ageing and facial lipoatrophy, especially in HIV patients [3].

There is evidence showing the ability of HA to interfere with viral replication in vitro. In particular, the replication of Herpes Simplex Virus type 2 [4], Respiratory Syncytial virus [5] and retroviruses [6] is inhibited by $\mathrm{HA}$, while the Adenovirus (ADV) one results enhanced [7]. Such limited and apparently controversial data demand further investigations in order to better understand the HA biological properties.

In this study we investigated the in vitro effects of a high molecular weight HA against a wide group of viruses covering a large spectrum of structural features and replication strategies: ADV-5, Coxsackievirus B5 (COXB5), Herpes Simplex Virus type 1 (HSV-1), Human Herpesvirus-6 (HHV-6), Influenza Virus A/ H1N1, Mumps Virus (MV), Porcine Parvovirus (PPV), Porcine Reproductive and Respiratory Syndrome Virus (PRRSV). We observed an antiviral activity against COXB5, HSV-1, MV, PPV and Influenza Virus encouraging the use of such compound as a medical tool in specific clinical circumstances.

\section{Materials and methods Hyaluronic Acid}

A high molecular HA (1.800 KD) in powder (IBSA, Istituto Biochimico SA, Lugano, $\mathrm{CH}$ ) was used. It was dissolved in Minimum Essential Medium (EMEM) at $8 \mathrm{mg} / \mathrm{ml}$ solution and sterilized by filtration through $0.45 \mu \mathrm{m}$ filters.

\section{Cells and Viruses}

The following cell lines were used to cultivate the different viruses: two monkey kidney lines, VERO cells for ADV-5, COXB5, HSV-1, and MV and MARC145 cells for PRRSV; the human T-leukaemia lymphoblast line JJHAN for HHV-6; the canine kidney line MDCK for Influenza Virus; the pig cell line PK15 for PPV. VERO, MARC145, PK15 and MDCK cells were cultured in EMEM added with 10\% (growth medium) or 5\% (maintenance medium) foetal bovine serum (FBS), penicillin $(100 \mathrm{U} / \mathrm{ml})$ and streptomycin $(100 \mu \mathrm{g} / \mathrm{ml})$; RPMI 1640 medium supplemented with $10 \%$ heat-inactivated FBS, penicillin $(100 \mathrm{U} / \mathrm{ml})$ and streptomycin $(100 \mu \mathrm{g} / \mathrm{ml})$ was used for JJHAN cells. All the cell lines were incubated at $37^{\circ} \mathrm{C}$ with $5 \% \mathrm{CO} 2$.

The viral strains of HSV-1, ADV-5, COXB5 and MV were clinical isolates, laboratory adapted through serial passages $(>50)$ on VERO cells. The Influenza Virus strain used was the highly neurotropic cell culture adapted WSN33 strain (A/H1N1). For HHV-6, the U1102 strain (variant A) was employed, whereas the two swine viruses tested were reference strains: NADL-2 for PPV and the ATCC strain (Cat. $\mathrm{N}^{\circ}$ VR-2402) for PRRSV. Batches of each virus were prepared, titrated on the suitable cell line and kept frozen at $-80^{\circ} \mathrm{C}$ until they were used for the experiments.

\section{Cytotoxicity Assay}

The MTT test [8] was used to evaluate the effects of the different concentrations of HA on cell viability. Briefly, serial dilutions of HA from $4 \mathrm{mg} / \mathrm{ml}$ to $0.5 \mathrm{mg} / \mathrm{ml}$ were prepared in maintenance medium and added $(250 \mu \mathrm{l} /$ well) to $24 \mathrm{hr}$-old cultures of each line. Each dilution was always tested in triplicate and, in each of the 3 experiments carried out, 3 control wells were included. The plates, with the different cell lines, were incubated at different times: $24 \mathrm{hrs}$ for VERO cells, $48 \mathrm{hrs}$ for MDCK and MARC 145 cells, 72 hrs for PK15 cells and 6 days for JJHAN cells. After incubation with HA, the MTT staining was carried out as previously described [9]. Cell viability was calculated as a percentage of the optical density (OD) of the HA-treated cultures in comparison with that one of the untreated controls $(100 \%$ viability).

\section{Assay of Cell Protection from Lysis}

Twenty-four hour growth VERO and MDCK cells in 96 well plates were exposed for $1 \mathrm{~h}$ to $\mathrm{HA}(4 \mathrm{mg} / \mathrm{ml})$; then a cell lysis solution Triton X-100 was added to each well at a final concentration of $0.1 \%$ and $0.5 \%$. After 5 ' for $0.1 \%$ concentration and 15 ' for $0,5 \%$ concentration, the lysis solution was removed and replaced with fresh medium. The cell viability was measured by MTT test and the survival of HA treated cells was compared with that one of HA untreated cultures. In each assay, cells, not exposed to lysis solutions, were used as controls (100\% viability). Three experiments were carried out, each one with samples in triplicate.

\section{Antiviral Assays}

The antiviral activity was ascertained by means of virus yield assays. Twenty-four hour growth cell cultures were infected with the different viruses at the following multiplicity of infection values: for COXB5, ADV-5 and MV 0.1 Tissue Culture Infectious Dose 50\% (TCID50)/cell; for HSV-1, 0.1 Plaque Forming Unit (PFU)/cell; for WSN33 virus, $0.1 \mathrm{PFU} /$ cell; for PPV, 0.1 TCID50/cell; for PRRSV, 0.1 TCID50/cell; for HHV-6, 0.1 TCID50/ cell. After $1 \mathrm{hr}$ adsorption at $37^{\circ} \mathrm{C}$, the inoculum was removed, the plates washed with $\mathrm{PBS}$ and the different dilutions of $\mathrm{HA}$, in maintenance medium, added to the 
cell cultures (each HA dilution was tested in triplicate). After $24 \mathrm{hr}$ incubation for COXB5, ADV-5, MV and HSV-1, $48 \mathrm{hr}$ for WSN33 and PRRSV, 72 hr for PPV and 6 days for HHV- 6 the plates were frozen and thawed three times and the viral yield was titrated by end-point titration for ADV, COXB5, MV, PPV, PRRSV, and HHV-6 and by plaque assay for HSV-1 and WSN33. As far as end-point titration is concerned, 10fold dilutions of each cell lysate were seeded on the 24 hr growth cells in a 96-well culture plate. After 3 days (6 days for HHV-6), the viral titre of each sample, expressed as TCID $50 / \mathrm{ml}$, was read taking into account the final dilution still showing the typical viral cytopathic effect and the results were elaborated using the Reed and Muench formula [10]. Plaque assays were carried out as follows. The samples from the HSV-1 and WSN33 experiments, serially diluted in 10-fold dilutions, were seeded on $24 \mathrm{hr}$ growth VERO or MDCK cells in 24 well plates. After $1 \mathrm{hr}$ adsorption, the viral inoculum was removed, the plates were washed with PBS and the maintenance medium, containing 0.9\% Noble Agar, was added. After $72 \mathrm{hr}$ incubation, the plates were stained with Neutral Red and the plaques counted: the resulting titre was expressed as PFU/ml. The selectivity index (SI) was calculated for each virus inhibited by HA as the ratio between the toxic dose 50 and the inhibiting dose 50. For each virus 3 experiments were carried out.

\section{Effects on the Antiviral Activity of Adding HA at Different Time Points}

Time course experiments were carried out with COXB5 and HSV-1 within a single replication cycle. HA (2 mg/ $\mathrm{ml}$ ) was added, at different time points, within $7 \mathrm{hr}$ for COXB5 and 18-20 h for HSV-1 according to each viral replication cycle. In parallel wells, HA was added together with the viral inoculum $(t=0)$. The virus yield was assessed by end point titration (for COXB5) or plaque assay (for HSV-1). For each virus, 3 experiments were carried out, each in duplicate.

\section{Virucidal Activity Assays}

The different viral inocula were exposed to $\mathrm{HA}$ at a final concentration of $4 \mathrm{mg} / \mathrm{ml}$, for $30^{\prime}$ at room temperature and then their residual infectivity was titrated on the suitable cells, as described above. A viral inoculum, treated with medium without HA was used as control for each virus. Two experiments for each virus were performed, each in duplicate.

\section{Results}

\section{Lack of Cytotoxicity Cell protection from lysis}

Initially, in order to rule out any direct cytotoxic effect of HA, dose-dependent experiments were performed exposing the five cell lines, employed in the experiments, to
HA for different times ( 1 to 6 days, according to the protocols used for virus growth) followed by MTT assay. We found modest cytotoxicity only at the highest HA concentration $(4 \mathrm{mg} / \mathrm{ml})$ which caused a OD reduction of about $20 \%$ in 4 of the 5 tested cell lines (Figure 1). At the lower concentrations, the OD reduction was about $10 \%$ or less. A slightly higher OD reduction (about 30\%) was observed on JJHAN cells at $4 \mathrm{mg} / \mathrm{ml}$, probably related to the longer exposition to HA of this cell line (6 days vs 1-3 days for the other cells).

\section{Cell Protection from Lysis}

With the aim of investigating whether HA may affect cell membrane stabilization, experiments, in which VERO and MDCK cells were pre-treated with HA and then exposed to a lysis solution (Triton X-100) were carried out. We found that both cell lines pre-treated for $1 \mathrm{hr}$ with $\mathrm{HA}$ at $4 \mathrm{mg} / \mathrm{ml}$ were significantly more resistant to lysis than the untreated controls. In particular, for VERO cells in the HA pre-treated groups, the cell viability was close to $100 \%$ with the mild treatment $\left(0.1 \%\right.$ for $\left.5^{\prime}\right)$ and $24.4 \%$ with the stronger one $(0.5 \%$ for 15 ), whereas in parallel groups, not pre-exposed to HA before lysis, the cell viability was reduced to $68.1 \%$ and $15.2 \%$, respectively (Figure 2). MDCK cells were more sensitive to lysis treatment, but also in this case the cells pre-treated with HA were more resistant to cell lysis $(38,2 \%$ and $21.1 \%$ the cell viability for the milder and the stronger treatment, respectively) than those not exposed to HA (30.4\% and $10.1 \%)$.

\section{Antiviral Activity by HA}

Virus yield experiments were carried out in the presence of HA to assess its antiviral activity. As shown in Figure $3 \mathrm{~A}, \mathrm{HA}$ exerted the most effective inhibition towards COXB5, with $3 \mathrm{Log}$ reduction of the virus yield at $4 \mathrm{mg} /$ $\mathrm{ml}$, and reduction of $3.5 \mathrm{Log}$ and $2 \mathrm{Log}$ at $2 \mathrm{mg} / \mathrm{ml}$ and 1 $\mathrm{mg} / \mathrm{ml}$, respectively. This strong inhibition was also confirmed by the SI (Appendix 1) which was 16.1. MV and Influenza Virus were highly inhibited too $(\mathrm{SI}=12.1$ and 11.9 , respectively): $1 \mathrm{Log}$ at $4 \mathrm{mg} / \mathrm{ml}$ and $2 \mathrm{mg} / \mathrm{ml}, 1.7 \mathrm{Log}$ reduction at $1 \mathrm{mg} / \mathrm{ml}$, for $\mathrm{MV}$ (Figure $3 \mathrm{~B}$ ) and about $1 \mathrm{Log}$ even at $1 \mathrm{mg} / \mathrm{ml}$ for WSN33 (Figure 3E). Two other viruses were inhibited, although to a lesser extent. HSV-1 and PPV showed $1 \mathrm{Log}$ reduction only at $4 \mathrm{mg} / \mathrm{ml}$ (Figure $3 \mathrm{C}$ and $2 \mathrm{~F}$ ) with lower SIs (4.8 and 3.6, respectively). No antiviral activity was observed with ADV-5 (Figure 3D), HHV-6 (Figure 3G) and PRSSV (Figure 3H).

\section{Effects on the Antiviral Activity of Adding HA at Different Time Points}

In order to investigate the timing of $\mathrm{HA}$ inhibition on replication cycle of HSV-1 and COXB5, kinetic 

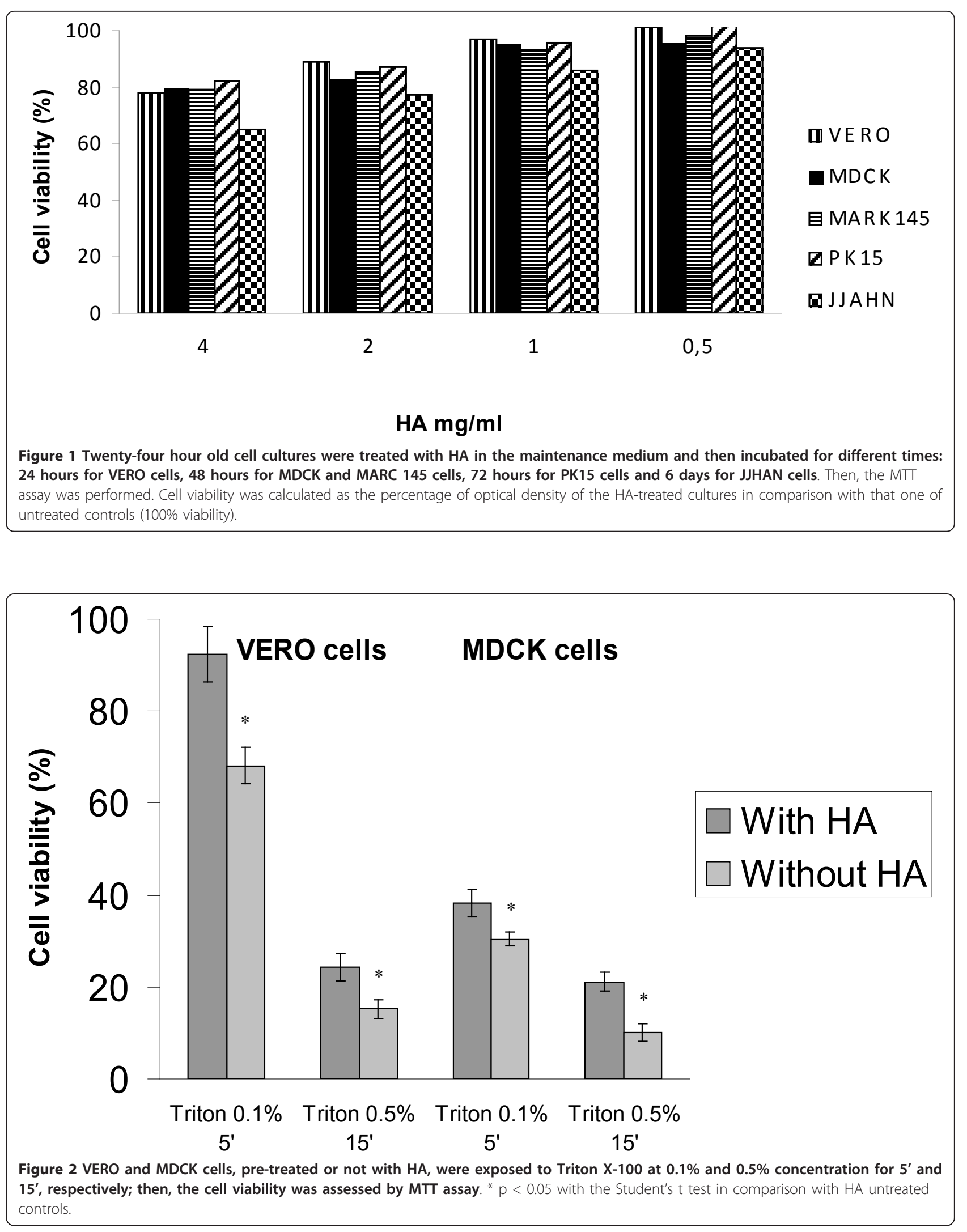

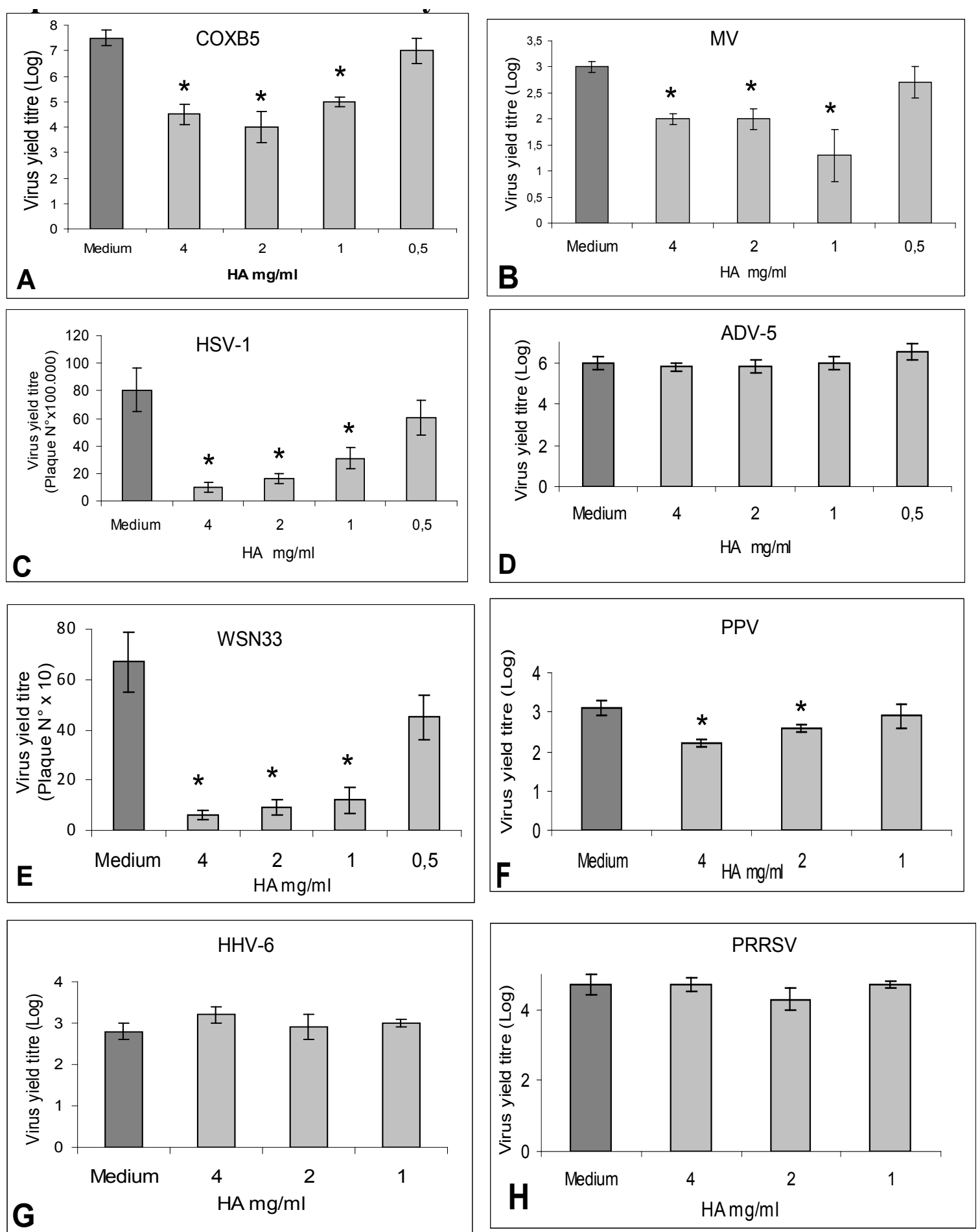

Figure 3 Different cell lines were infected with COXB5 (panel A), MV (panel B), HSV-1 (panel C), ADV-5 (panel D), WSN33 (panel E), PPV (panel F), HHV-6 (panel G), PRRSV (panel H) and then exposed to HA at different concentrations in the maintenance medium. The virus yield was titrated by end point titration for COXB5, MV, ADV-5, PPV, HHV-6 and PRRSV (results expressed as Log of the TCID50) and by plaque assay for HSV-1 and WSN33 (results expressed as PFU/ml). ${ }^{*} p<0.05$ with the Student's t test in comparison with HA untreated controls. 
experiments were designed. HA was added to the infected cells at different time points, during a single replication cycle. Both COXB5 (Figure 4A) and HSV-1 (Figure 4B) growth were consistently inhibited by HA, regardless of the time of addition.

\section{Lack of HA Direct Virucidal Activity}

With the aim to assess whether HA could directly inactivate virus particles, each viral inoculum was resuspended with HA for 30 minutes before cell infection.
The results of these experiments showed that the virus titre was not significantly reduced $(<0,5 \mathrm{Log})$ after HA treatment, indicating no virucidal activity by HA against any of the tested viruses (data not shown).

\section{Discussion}

This paper provides a new information on the biological properties of HA, describing its antiviral in vitro activity against 5 viruses, with different structural and biological features.
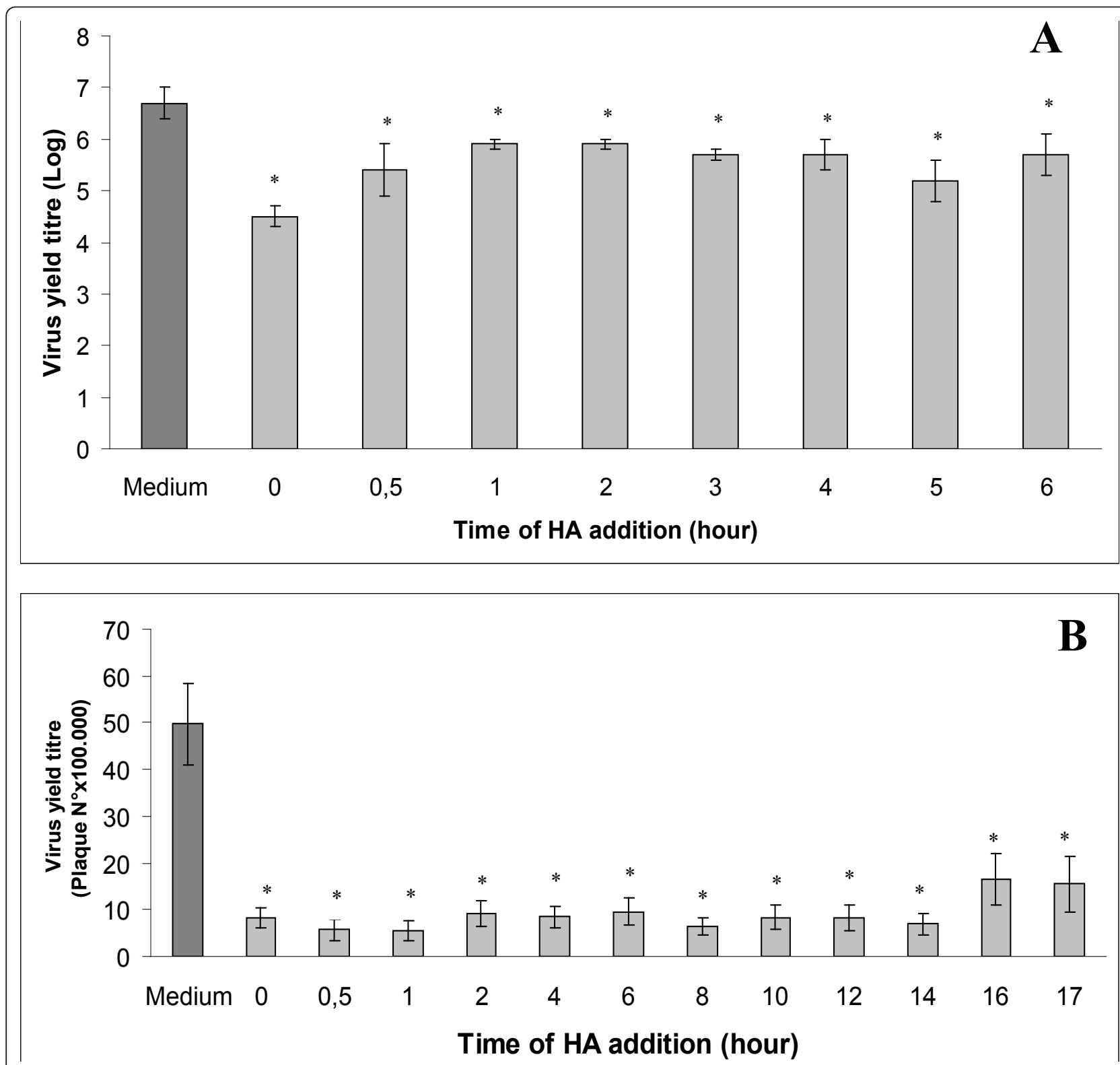

Figure $4 \mathrm{HA}$ ( $2 \mathrm{mg} / \mathrm{ml}$ ) was added at different time points within a single viral replication cycle (7 h for COXB5, 18-20 $\mathrm{h}$ for HSV-1). In parallel wells, HA was added together with the virus inoculum $(T=0)$. At the end of the replication cycle, cell cultures were frozen and the virus yield was titrated by end point titration (COXB5, panel A) or plaque assay (HSV-1, panel B). The results are expressed as Log of the TCID50 in panel A, as PFU/ml in panel B. ${ }^{*} p<0.05$ with the Student's t test in comparison with HA untreated controls. 
HA is a non-sulfated glycosaminoglycan widely present in the extracellular matrix of soft tissues and in several biologic fluids [2]. Experimental and clinical data demonstrate the involvement of HA in structure maintenance, moisturizing, tissue lubrication and wound healing. These properties, associated with an excellent safety profile, are exploited in medical practice as well as in aesthetic and cosmetic fields [2,3]. Furthermore, initial evidence also ascribes antimicrobial properties to HA [11-13], adding further appeal to the HA-containing products because of the beneficial effects probably deriving from its antimicrobial properties. Here, we have demonstrated a wide spectrum antiviral activity of a high molecular weight HA. The most effective inhibition is observed against COXB5, MV and Influenza Virus WSN33 (A/H1N1) and it is interesting that the phenomenon is retained even at a concentration $(1 \mathrm{mg} / \mathrm{ml})$ lower than that one commonly used for clinical or cosmetic applications. The high SIs displayed by HA for these viruses document a strong antiviral activity not related to cytotoxicity. HSV-1 and PPV are also inhibited by HA, but only at the highest concentration (4 $\mathrm{mg} / \mathrm{ml}$ ): the SIs are consequently lower. No activity is ever observed against ADV-5, HHV-6, PRRSV. The HA failure to inhibit ADV is not unexpected since, according to Chaudhuri [7], HA enhances ADV replication in vivo and, though to a lesser extent, also in vitro. The different cell system we used may account for the lack of replication enhancement observed in our experiments.

Our findings provide evidence on the effects of HA on a variety of RNA and DNA viruses, with or without the lipidic envelope, characterized by very different replication strategies. Therefore, we can speculate that HA antiviral mechanism(s) probably involves general/nonspecific host cell-virus interaction at membrane level, such as virus entry or release, rather than restricted, virus-specific events occurring inside the cell. This speculation is supported by the kinetic results showing that both COXB5 and HSV-1 are growth inhibited irrespective of the time of HA addition during the virus replication cycle. In line with this hypothesis, we may suggest that HA, known to have a heavy ionic charge, may alter the electrostatic interactions between virus and cell receptors and/or other cell membrane components, thus in turn affecting virus entry and/or exit. Literature data substantiate this hypothesis. Dengue virus uses heparansulphate (HS) as a cell receptor: different types of HA, interacting with the virus envelope glycoprotein, responsible for virus attachment to HS, are able to inhibit virus attachment and entry [14]. HSV-1 recognizes HS as a receptor too and it has been reported that molecules, affecting the interaction between HSV-1 envelope glycoproteins and HS, are able to reduce the virus growth [15-17]. Several Enteroviruses (including some
Coxsackieviruses) are reported to interact with HS for virus entry [18-20]. The results of our kinetic experiments seem to suggest that virus release is also inhibited by HA. Notoriously, this step involves host cell membrane. HSV -1 and COXB5 are released by different mechanisms: HSV-1 by trans-membrane trafficking of vesicles, while COXB5 by cell membrane lysis. Therefore we may assume that the mechanism, by which HA inhibits virus release, has to be non-specific. The results observed in the assay of cell protection from lysis, showing that cells exposed to HA are more resistant to cell lysis, suggest that HA stabilizes cell membranes. This modification could impair any membrane involving process, such as envelope fusion with cell membrane, vesicle fusion and membrane disruption. We have observed that in the antiviral experiments with MV, a syncytiogen virus, not only virus yield was reduced in the presence of HA, but syncytia size also appeared at light microscope observation smaller than those ones of the control cultures. This HA stabilizing activity on membranes indirectly implies that cell exposure to HA inhibits virus entry and/or exit. Finally, the lack of appreciable virucidal activity by HA, against all the viruses under study, rules out the possibility of a direct virus inactivation by HA and it also supports the idea that the steps, involving virus-cell membrane interaction, are preferentially, if not exclusively, affected by HA.

In conclusions, our study provides a wide spectrum demonstration of the antiviral activity by HA, opening new perspectives in prophylaxis and therapy of some viral diseases. The hypothesis of specifically counteracting cell-virus attachment and viral release, by local administration of HA, is very appealing especially for oral, genital and ano-rectal anatomical areas, where compound(s) can be administered as creams, gels or wash solutions. Many HA-based commercial products already available for topic use have HA concentrations much higher or equal to those we found active against different viruses: so it can be hypothesized that effective concentrations can be locally reached. The inhibitory activity observed against HSV-1 is particularly interesting since $\mathrm{HA}$ is the basic component of mouthwash solutions and ophthalmic drops, used as artificial tears. According to our findings, HA may be also considered/ included as an antiviral agent in the treatment of HSV1 -associated stomatitis and kerato-conjunctivitis in this kind of preparations. Moreover, since Enteroviruses are often responsible for a childhood form of vesicular stomatitis as well as respiratory diseases, the present findings on Coxsackievirus inhibition may open new perspectives for oral administration of HA as natural atoxic medical treatment of newborns and babies. Similarly, the anti-influenza virus activity observed might be exploited in nasal sprays to locally reduce viral 
replication. Moreover, HA has been demonstrated to have pro-inflammatory activity. Low weight HA fragmentation products and, in the presence of IFN $\gamma$, even high molecular weight HA molecules can also activate innate immunity mechanisms through Toll-like Receptor 4 and CD44 [21,22]. This pro-inflamamtory activity may contribute to counteract virus replication and spread in vivo.

In conclusion, our findings strongly support the use of this safe glycosaminoglycan in clinical practice as a potential antiviral compound, both for disease prevention and treatment. Further clinical trials on this topic are required to better understand the antiviral activity of this compound.

\section{Appendix 1 - Selectivity indexes of HA}

Coxsackievirus B5 - 16.1

Mumps virus - 12.1

Influenza A/H1N1/WSN33 - 11.9

Herpes Simplex Virus-1 - 4.8

Porcine Parvo - 3.6

Selectivity indexes were calculated for those viruses inhibited by $\mathrm{HA}$ as the ratio between the toxic dose 50 and the inhibiting dose 50 .

\section{Abbreviations}

ADV-5: Adenovirus-5; COXB5: Coxsackievirus B5; EMEM: Eagle Minimum Essential Medium; FBS: Foetal Bovine Serum; HHV-6: Human Herpes Virus-6; HSV-1: Herpes Simplex Virus-1; HS: heparan sulphate; MV: Mumps Virus; PFU: Plaque Forming Unit; PPV: Porcine Parvovirus; PRRSV: Porcine Reproductive and Respiratory Syndrome Virus; OD: Optical Density; SI: selectivity index; TCID50: Tissue Culture Infectious Dose 50

\section{Author details}

${ }^{1}$ Department of Public Health Sciences, University of Modena and Reggio Emilia, Modena, Italy. ${ }^{2}$ Department of Laboratories, Pathological Anatomy and Legal Medicine, University of Modena and Reggio Emilia, Italy. ${ }^{3}$ Department of Biological and Biomedical Sciences, Glasgow Caledonian University, Glasgow, UK. ${ }^{4}$ Department of General Surgery and Surgical Specialties, University of Modena and Reggio Emilia, Modena, Italy.

\section{Authors' contributions}

The authors hereby certify that all work contained in this paper is original work of CC, AC, MS, BC, RN, AA, EB, TI and BP. The authors claim full responsibility for the contents of the article. The authors contributed equally to this work. This article was not supported by grants.

\section{Competing interests}

The authors certify that there is no conflict of interest with any financial organization regarding the material discussed in the manuscript.

Received: 24 September 2010 Accepted: 25 March 2011 Published: 25 March 2011

\section{References}

1. Laurent TC, Fraser JR: Hyaluronan. FASEB J 1992, 6(7):2397-2404

2. Goa KL, Benfield P: Hyaluronic acid. A review of its pharmacology and use as a surgical aid in ophthalmology, and its therapeutic potential in joint disease and wound healing. Drugs 1994, 47(3):536-566.

3. Bissett DL: Glucosamine: an ingredient with skin and other benefits. J Cosm Dermatol 2006, 5(4):309-315.
4. Tiunnikov Gl, Kostina GA, Radaeva IF, Bakulina LF: Effects of hyaluronic acid preparation on the development of herpetic infection in cell culture. Vopr Virusol 2002, 47(1):37-39.

5. Hallak LK, Collins PL, Knudson W, Peeples ME: Iduronic acid-containing glycosaminoglycans on target cells are required for efficient respiratory syncytial virus infection. Virology 2000, 271(2):264-275

6. Le Doux JM, Morgan JR, Yarmush ML: Differential inhibition of retrovirus transduction by proteoglycans and free glycosaminoglycans. Biotechnol Prog 1999, 15(3):397-406.

7. Chaudhuri SR, Mallam JN, Chévez-Barrios P, Wadhwa L, Ng P, Hurwitz MY, Hurwitz RL: Modulation of adenoviral transduction in vitro and in vivo by hyaluronan and its receptor CD44. Mol Ther 2007, 15(3):566-70.

8. Denizot F, Lang R: Rapid colorimetric assay for cell growth and survival. Modifications to the tetrazolium dye procedure giving improved sensitivity and reliability. J Immunol Methods 1986, 89(2):271-277.

9. Cermelli C, Fabio A, Fabio G, Quaglio P: Effect of Eucalyptus Essential Oil on Respiratory Bacteria and Viruses. Curr Microbiol 2008, 56:89-92.

10. Lennette EH: General principles underlying laboratory diagnosis of virus and rickettsia infections. In Diagnostic procedures of Virus and Rickettsia Disease. Edited by: Lennette EH, Schmidt NH. New York, American Public Health Association; 1964:45

11. Carlson GA, Dragoo JL, Samimi B, Bruckner DA, Bernard GW, Hedrick M, Benhaim P: Bacteriostatic properties of biomatrices against common orthopaedic pathogens. Biochem Biophys Res Commun 2004, 321(2):472-478

12. Pirnazar P, Wolinsky L, Nachnani S, Hake S, Pilloni A, Bernard GW: Bacteriostatic effects of hyaluronic acid. J Periodontol 1999, 70(4):370-374.

13. Zaleski KJ, Kolodka T, Cywes-Bentley C, McLoughlin RM, Delaney ML, Charlton BT, Johnson W, Tsianabos AO: Hyaluronic acid binding peptides prevent experimental staphylococcal wound infection. Antimicrob Agents Chemother 2006, 50(11):3856-60.

14. Marks RM, Lu H, Sundaresan R, Toida T, Suzuki A, Imanari T, Hernàiz MJ, Lindhardt RJ: Probing the interaction of dengue virus envelope protein with heparin: assessment of glycosaminoglycan-derived inhibitors. J Med Chem 2001, 44(13):2178-87.

15. O'Donnell CD, Shukla D: A novel function of heparan sulfate in the regulation of cell-cell fusion. J Biol Chem 2009, 284(43):29654-29665.

16. Tiwari V, ten Dam GB, Yue BY, van Kuppevelt TH, Shukla D: Role of 3-Osulfated heparan sulfate in virus-induced polykaryocyte formation. FEBS Lett 2007, 581(23):4468-4472.

17. WuDunn D, Spear PG: Initial interaction of herpes simplex virus with cells is binding to heparan sulfate. J Virol 1989, 63:52-58.

18. Escribano-Romero E, Jimenez-Clavero MA, Gomes P, Garcia-Ranea JR, Ley V: Heparan sulphate mediates swine vesicular disease virus attachment to the host cell. J Gen Virol 2004, 85(Pt 3):653-663.

19. Zautner AE, Körner U, Henke A, Badorff C, Schmidtke M: N- and 6-Osulfated heparan sulfates mediate internalization of coxsackievirus B3 variant PD into CHO-K1 cells. J Virol 2006, 77(18):10071-10077.

20. Zautner AE, Jahn B, Hammerschmidt E, Wutzler P, Schmidtke M: Heparan sulfates and coxsackievirus-adenovirus receptor: each one mediates coxsackievirus B3 PD infection. J Virol 2003, 80(13):6629-6636.

21. Termeer C, Benedix F, Sleeman J, Fieber C, Voith U, Ahrens T, Miyake K, Freudenberg M, Galanos C, Simon JC: Oligosaccharides of hyaluronan activate dendritic cells via Toll-like receptor 4. J Exp Med 2002, 195:99-111.

22. Wallet MA, Wallet SM, Guiulfo G, Sleasman JW, Goodenow MM: IFNy primes macrophages for inflammatory activation by high molecular weight hyaluronan. Cell Immunol 2010, 262:84-88.

doi:10.1186/1743-422X-8-141

Cite this article as: Cermelli et al:: In vitro evaluation of antiviral and virucidal activity of a high molecular weight hyaluronic acid. Virology Journal 2011 8:141. 